\title{
A Discussion on Functional Localization of Higher Vocational Education
}

\author{
Xianzhang Xin $^{1, a}$, Hongxia Zhao ${ }^{1, b}$ \\ ${ }^{1}$ Dalian Vocational and Technical College, Dalian 116035, China \\ axinxz@hotmail.com, ’1003967953@qq.com
}

Key words: higher vocational education, craftsmanship, application-orientation

\begin{abstract}
Higher vocational education, via laborers' vocational activities, influences a country in the fields of economy, technology, culture and military affairs when the products are finally made, which makes higher education the basis of a country's national competitiveness. We must focus on the functional localization, modernization, application of higher vocational education, and lay emphasis on the cultivation and popularization of craftsmanship.
\end{abstract}

\section{1 .Introduction}

The key to develop higher vocational education with high quality lies in the precise localization of higher vocational education and fully release the positive energy it contains. Ever since the industrial era, higher vocational education has increasingly servedas the basis to advance the economy and society in a country and yielded the direct and profound effects.

\section{2 . The basic functions of higher vocational education}

While surveying the history of higher vocational education in different countries, it is found that all countries share 3 similarities among the tremendous differences in cognition, attention on higher vocational education of different countries and huge differences in different eras of a same country.

2 . 1 Higher vocational education is the basis to level up the national quality

The utmost value of education is to promote all-round development of a human spiritually and to help the educatee to achieve a satisfactory and sound character. As a type of higher education, the utmost value of higher vocational education is surely to shape an educatee with satisfactory and sound personality. As an important ingredient of national education system and talents pool, higher vocational education takes the responsibilities of educating diversified talents, instructing skills, promoting employment and cultivating entrepreneurship education. [1] Under the current context of global politics, economy and safety, it is the workforce's professional qualities that serve as the most direct, important and decisive role in weighing a country's survival and advancement. Professional qualities take up the most substantial content of national quality.

2. 2 Higher vocational education can effectively facilitate the equal access to education

The pursuit of equality is regarded as the most important target of human society, while the equal access to education is the significant content in the pursuit of equality. In "A Theory of Justice", American thinker John Rawls puts that the poorer family background a person gets, the less access he will have to make a living, and the more extra education he will need to compensate for his previous generations'deprivation of education opportunities. Since 1960s, developed countries has begun to undertake measures to alter the over-emphasis on the elite education and socialize the higher education, aiming at entitling more people to have access to higher education, raising the education coverage and thus realizing the equal access to education. 


\section{2 . 3 Higher vocational education can help social members to realize their dreams}

The realization of higher vocational education not only facilitates the full, decent, qualified employment, but also offers the substantive impetus for the transformation of economy in a country. Vocational education should shape the cultural values to appraise the talents with practice and achievements and all the society should value skilled and technical talents via cultivating these talents with a good virtue, knowledge and humanistic qualities. Only in this way can vocational education make every student become successful, and therefore produce a sound talents pool to develop the national industry.

\section{3 .Craftsmanship remains the soul of modern vocational education}

Craftsmanship has always been the soul of modern vocational education and an ideal for a labor, which, in fact, easily becomes the blind area for vocational colleges at all levels to carry out the vocational education.

\section{3 . 1 How to comprehend craftsmanship}

Craftsman, in essence, refers to the special talent who inherits the specific professional spirits and specialized skills via special training. The one who deserves to be called craftsman must be closely related with some industrial civilization development. The person who just make the DIY, the little makings and simple technical products couldn't be regarded as a craftsman.

Generally speaking, to achieve the craftsmanship, a labor should have a strong sense of professionalization, dedication and perfection, strive for professional excellence in his career life and obtain the integrity, fidelity and dedication in his career. The true craftsmanship embodies the trinity of professional spirits, occupational attitudes and humanistic literacy.

\subsection{Social value of craftsmanship}

First, craftsmanship is the fruit of highly developed industrialized civilization. From this perspective, we can adopt a proper understanding towards spiritual achievements of industrial civilization, and our comprehension of vocational education could act as the bridge connecting to the world civilization. Taking service as the principle and employment as the orientation, vocational education should take craftsmanship as the fundament and guidance in nature.

Second, craftsmanship remains the guiding ideology to develop the vocational education. A series of measures should be carried out to refine the talents-cultivating model, professional curriculum textbooks and educational methods, which endows the education practice with humanity, value and ideology.

Third, craftsmanship symbolizes the soft power of vocational education. Introducing the craftsmanship into vocational education and widely disseminate it to the society bears a significant role in transforming the image of vocational education and altering the social evaluation towards it.

\section{3 . 3 How to cultivate craftsmanship}

First, based on the internal principles of vocational education, vocational colleges should abandon the constraints of general education, fully comprehend the value of craftsmanship on vocational education, and consequently laid a solid foundation for deepening the renovation of vocational education.

Second, vocational colleges should integrate the craftsmanship into the whole process of educational innovation and enhance the rational education in curriculum design, field training, ideological \&political education, and post-practice. Via the necessary learning of humanistic curriculum, training of career plan and guiding of skills training, it makes the whole education process take on the characteristics of comprehensive quality education and sustainable growth cultivation for students. 
Third, vocational colleges should take the advantages of talent-cultivating mode innovation under college-enterprise cooperation to implement the integration between industry and vocational education and enhance the cultivation of craftsmanship, thus making craftsmanship, skills training incorporate each other and finally be internalized in the spirits of the students.

Fourth, vocational colleges should take the cultivation ofcraftsmanship as the hitting-point and commanding-height while building their own cultural soft power. On one hand, campus culture, rich in craftsmanship, should be cultivated in colleges. On the other hand,craftsmanship should be spread to the whole society with its cultural soft power. Clearly enough, only by carrying forward thecraftsmanship can it truly create a social atmosphere which can enlighten people to be pride of labor, value skills and highly focus on innovation and therefore build the social foundation for the cultural soft power of vocational education to survive. [2]

\section{Time category cannot be ignored when studying the functional localization of higher vocational education}

Higher vocational education is a historical category, whose development patterns and connotation possess distinct characteristics of the times; in the meantime, modern higher vocational education is influenced and restricted by economy, politics, history, culture and etc., particularly, social productive forces are decisive factors in developing vocational education. Only by systematically analyzing the factors to affect the development of vocational education, can we accurately grasp the connotation of vocational education. Only by paying full attention to the eras and phases of higher vocational education while studying its connotation, system and development path, can we make it possible to achieve the scientific development of higher vocational education in China.

Modernity is more than a concept oftime or the concept ofmodernization that is often mentioned in our daily life. Having instrumental rationality and value rationality, Modernityshould be used as a new way of thinking about problems in an era of globalization and informationization to meet with economic development, industrial upgrading and apply consciously the universal standard of human civilization to promote the development of the whole society. The modernity of higher vocational education is mainly embodied in the synchronization and coordination between the transformation of economic development mode and upgrading of industry configuration. Countries need to carry out scientific design and practice on vocational education system in line with their specific national conditions, and implement top-level design and path selection from the perspective of coordination between national economy and society, thus forming a scientific plan for the future development of vocational education.

\section{The development of modern higher vocational education cannot be isolated from its application-oriented characteristics}

Modern vocational education is an important support for the development of modern industry and an important guarantee to train technical and skilled talents with high-quality. We must unswervingly adhere to the essence of application-oriented vocational education in promoting vocational education to achieve innovative development.

\section{5 . 1 Building overpass-bridge to smooth convergence channels}

Higher vocational education should realize longitudinal convergence between higher vocational education and secondary vocational education. Thevocational education systems in developed countries are mostly in the shape of a spinning-top which is wide at the top and narrow at the bottom while the vocational education in China is in the shape of pagoda which is narrow at the 
top and wide at the bottom that requires to compress the secondary vocational education if necessary, maintain the current higher vocational education and expand the education for application-oriented undergraduates and professional graduates. Only in this way can we meet the students' aspirations of further studies and the craving of industrial upgrading for skilled and technical talents and professionals.

Higher vocational education needs to realize two-way flow between general education and vocational education. At present it is much easier for students of general education to get vocational education while the reverse it is much more difficult. So, it is necessary to speed up the establishment of framework for equivalent qualification accreditation between vocational education and general education, lifting the proportion restriction on the two-way flow between two educations. When students are up to corresponding requirements of learning in either of education, cross-flow and exchange of students should be allowed.

\section{2 Emphasizing on innovation to change the traditional model}

The government should push some colleges to change their traditional ways of thinking and mode of running a college to re-position their status scientifically. Based on local economy and society, vocational colleges should take their own advantages into consideration and undertake a series of innovation in ideas of running a college, system of administrating a college, major construction, teaching mode, talents-cultivating mode, teaching staff building, management, service and etc. Educational authorities should establish a sound and flexible curriculum adjustment mechanism, highlighting the technical-specification-based teaching method, project-based teaching method, case-based teaching method, and promoting various forms of innovations in task-driven teaching, project-oriented teaching, module-based teaching, work-integrated learning and etc., thus enabling students to develop the capabilities to apply their professionals, to learn, and to adapt to the future jobs.

\section{5 . 3 Making policies first to get rid of transformation resistance next}

The first step to deeply promote the local general universities to transform into application-oriented type is the transformation on the policy level. By offering much guidance, the local government should plan the industry as a whole, establish pilot transformation universities and then gradually promote it. Local government should define the responsibilities of industries and enterprises to participate in talents cultivation and carry out regulations and incentive policies timely that can help establish deep integration of industry, enterprises and universities. The autonomous right of colleges and universities in introducing talents should be expanded, enrollment system be reformed, multiple system in enrollment be explored, cooperation among industries, enterprises and colleges in enrollment be encouraged; International intercollegiate exchanges and cooperation should be expanded, multi-channel joint cooperation with overseas universities be widened, student-exchange program be developed, mutual accreditation of credits and mutual awarding of degrees be launched, teachers' participation in academic exchanges and scientific research be supported.

\section{5 . 4 Classifying scientifically to stimulate the vitality of teachers}

The teaching staff from higher vocational education possesses two characteristics, of which one is higherand the other is vocational. The so-called higher refers to higher education with all the attributes of higher education. The so-called vocational refers to the vocational education with the attributes of market and skills. Higher vocational teaching staff is a type of high qualified teachers that gathers the capabilities of production-education-research, which makes them different from general university faculty or enterprise master workers.Higher vocational teaching staff possesses the characteristics of bothenterprises and public institutions. The continuous identity conversion 
between enterprises and public institutions limits the growth of higher vocational teachers. Therefore, breaking the current system is not only the objective requirement to build the higher vocational teaching staff, but also the best breakthrough to reform the educational system.

Relevant government sectors should put higher vocational colleges on the pilot list of deepening the reform of the educational system and undertake the personnel system innovation first particularly. The core is to completely carry out de-administration of management, fully release the right of promoting or demoting staff based on per-student appropriation, implement real employment system, and establish an effective two-way mechanisms of staff flowbetween enterprises and public institutions. Only by breaking the personnel system barriers, broadening the entrance and opening the exit for talents and strengthening the job responsibilities can we build vocational college teaching staff with full vitality.

\section{6 .Summary}

Higher vocational education, mostly connected with the economy and society, supports the realization of new industrialization, information technology, urbanization and agricultural modernization, thus playing an irreplaceable role in promoting the realization of the Chinese Dream. To transform the economic development mode and develop modern industrial system requires high-level skilled and technical talents. From the experience of the vocational education in developed countries and regions, vocational education needs to improve its development framework and therefore better serve the regional economy and promote comprehensive national strength.

\section{References}

[1] Yan-dong Liu, Speech - Deeping Reform, Accelerating Development and Creating New Era of Our Modern Vocational Education, The Conference of National Higher Vocational Education of China, June, 2014.

[2] Xiao-lu Li, Craftsmanship-The Soul of Vocational Education, Guangming Daily, May, $16^{\text {th }}$, 2016. 